\title{
Are notifications a challenge for older people?: a study comparing two types of notifications
}

\author{
Iyubanit Rodríguez \\ Pontificia Universidad \\ Católica de Chile \\ iyubanit@uc.cl
}

\author{
Carolina Fuentes \\ Pontificia Universidad \\ Católica de Chile \\ cjfuentes@uc.cl
}

\author{
Valeria Herskovic \\ Pontificia Universidad \\ Católica de Chile \\ vherskovic@uc.cl
}

\author{
José A. Pino \\ DCC-Universidad de Chile \\ jpino@dcc.uchile.cl
}

\begin{abstract}
Elderly users are usually not the target of design of mobile applications, and they may have cognitive and physical difficulties. Mobile notifications may help them remember to use an application, promoting adoption and allowing them to become content providers. We developed a mobile application, QuestionReport, that asks users one question per day, and implemented two types of notifications: one that is activated at the same time each day, and one that is activated while using the smartphone. We tested both notification types with 18 users over a period of 8 days, measuring the time it took to answer the question after receiving the notification and their perceptions about each notification style. We found that the ideal time for users to receive a notification depends on their employment status and that users with low digital skills have less confidence in their abilities to use a mobile application such as QuestionReport.
\end{abstract}

Keywords-notifications; elderly people; user experience

\section{INTRODUCTION}

The world's population is rapidly aging. By 2050, it is estimated that over $22 \%$ of people will be over 60 years old $^{1} ; 72.4 \%$ of elderly people have a mobile phone that they use to talk to family and friends and for emergencies; $13.2 \%$ normally use a computer and $9.8 \%$ regularly use the Internet. [3], but they are generally not the target of design of mobile applications [17]. Elderly people are users of technology, although use may be affected by motor difficulties [22] and memory loss [40].

Digital skills are the set of knowledge, skills and attitudes required to perform tasks, solve problems, communicate, manage information, collaborate, create and share content using information and communication technologies [13]. Although, digital skills are necessary to function in today's society, the required skills constantly change, in line with the rapidly evolving technologies [13] and elderly people often lag behind these changes.

Notifications may help older adults remember to use an application [40] while allowing greater technology adoption for adults with declining memory and information processing capabilities [43]. For example, assisted living facilities that use unobtrusive sensors (physiological and

\footnotetext{
${ }^{1}$ United Nations Population Fund, http://www.unfpa.org/
}

environmental) to detect seniors' activities and state may require notifying them with suggestions or relevant detected data (which may be urgent, e.g. changes in heart rate). However, notifications may cause users stress and frustration [1], [41] and these problems may be exacerbated in older adults, who are frequently wary of new technology [35]. The objective of this research is to explore the attitudes of older adults towards mobile applications and notifications, and to study two notification approaches to discover which is most suitable for elderly users.

To understand older users' attitudes towards notifications, we designed a simple mobile application called QuestionReport that asks a question once a day and incorporates two types of notification times: (1) at a time chosen by the user, and (2) while the user is using his/her phone (unlocked). Then, we recruited 18 adults over 50 years in Costa Rica and Chile, who used the application under each notification type for 4 days. We measured the time taken to complete the task (answer the question), took notes of participants' comments and questions about the application, and asked them to complete questionnaires regarding their digital skills, pressure/tension, usability, and participant opinions. We analyzed the data by comparing participants according to age group, digital skill level and occupation, and analyzed participant opinions using thematic analysis.

The main research questions guiding this research are the following ones.

1) Do older adults prefer to choose to specific time to receive notifications or would they rather receive them at any time while they are using their device?

2) Is the time taken to answer an application notification related to the user's digital skills or occupation?

3) Does receiving a mobile application notification produce stress in older adults?

This paper is organized as follows. First, we discuss related work, considering characteristics of elderly adults and work done on notifications. Then, we describe the design and characteristics of our prototype, QuestionReport. Section IV describes our methodology, then section V presents the results and section VI the discussion. Finally, section VII 
presents our conclusions and discusses possible future work.

\section{RELATED WORK}

\section{A. Elderly users and functioning loss}

There is no clear consensus on from what age adults are considered older adults or elderly. In 1875 - and still in some regions of the world - an older adult was a person over 50 years old [26]. The United Nations generally considers older adults to be over 60 , and in many countries the age of retirement is 60 to 65 [17]. Some studies use the term oldest old to refer to adults who are over 80 years old [24]. The aging process is not uniform across the population, due to differences in genetics, lifestyle and health [32]. In this study, we recruited adults with low or basic digital skills who were over 50 years old, and older adults over 60 years old with any digital skill levels. We included both groups to be able to see if any differences or trends became apparent in both age groups.

Functioning loss is "the inability to perform certain physical or mental tasks, such as lifting, walking, balancing, reading, writing, counting, and using fingers and hands to grasp and open, and it occurs at a later age" [11]. Elderly people may suffer cognitive and physical problems [34]. Regarding cognitive decline, some studies suggest that working memory and short-term recall and speed of information processing gradually decline throughout adulthood [43]. These characteristics of aging imply that senior adults may have some motor difficulties in using technologies [22] and in remembering how to use them [40].

\section{B. Notifications, Triggers and Timing}

The term notification refers to "a visual, auditory or haptic signal generated by an application or service that transmits information to a user outside the current focus of attention" [20]. Applications that intend to change user behavior require motivation, ability and a trigger that reminds the user to get the task done [15]. Timing is especially important and frequently forgotten: the trigger must be received at a moment when the user is able and motivated to do the task [15].

Notifications may be disruptive, annoying [41], and impact the usability of a mobile system [10]. Interruptions can reduce the performance of the primary task [42] and affect the user's mood [1]. Therefore, an overload of notifications may lead to technostress, which is "the psychological pressure on humans caused by technology" [29].

There has been some research on the attitude of users towards notifications regarding information overload and how this could generate stress [41], or finding the best time to send a notification by processing data, detecting context information and predicting when the time is right to make a message available [25]. Another approach, based on a predictive model, suggests the best moment to deliver notifications [23]. None of these studies, however, has focused on elderly people.

Some notification systems are actually designed to be used by medical staff, caregivers and family members, e.g. a system that sends alerts in real time to help caregivers know about risky situations in geriatric residences [33]. Examples of these systems are systems that allow monitoring of older adults by nurses [4], alerting caregivers about the posture of elderly people (captured by a webcam) [31], and a notification framework that allows the management of several applications and alerts in an assisted living home [6].

However, elderly people should also be considered as digital content producers [39]. Some studies have focused on older adults as the users, e.g. helping to plan future events and remember information about upcoming events at the right time. [18] and use voice notifications for smart homes [28]. Warnock et al. (2013) studied the different types of notifications for elderly users, finding that independent of any modality of notification (e.g a notification that requires an answer or can be ignored), younger and older users are affected in the same way when the performance and distraction are measured [38]. Umezu et al. evaluated the usefulness of a mobile application integrating older adults into social activities. They found that half of the tested elderly users complained that the notifications were not provided at the right time [37].

\section{Do notifications cause technostress?}

Person-environment theory posits that there should be a balance between an individual and his/her work environment [16]. According to this model, a mismatch between the task and the individual's skills is related to technostress [2]. The Fogg Behavior Model (FBM) [15] stresses that to get users to accomplish a target behavior, three main factors have to be in place: motivation, ability and a trigger.

In our case, the target behavior is answering a question, which is a simple task. However, as the FBM states, users' ability, or digital skills, are a critical factor, as is the timing of the trigger. Passive (non-interrupting) notifications at a time selected by the user have been found to increase data logging [5]. However, using a predetermined time may not leverage other opportunities to ask users for input, e.g. when they are already using their phone.

Therefore, this paper aims to determine whether elderly users prefer to receive notifications at a set time or when they are using their phone, with the aim of reducing technostress. An application such as this may allow elderly users to become digital content providers who can report e.g. health information to their families and healthcare providers.

\section{DESIGN OF THE QuestionReport APPLICATION}

We implemented a mobile application to answer a random question per day. The questions set is composed of 10 
questions and the user must indicate her/his answer by selecting a number from 0 to 10 . In order to remind the user to answer the question, the system sends out one daily notification (see Figure 1). The system provides two different types of notifications:



Figure 1. Diagram of application QuestionReport.

1) Fixed Time notification (FTN): this notification is activated at a specific time of day, which is chosen by the user when the application is installed. The notification is sent every day at the same time (see Figure 2).

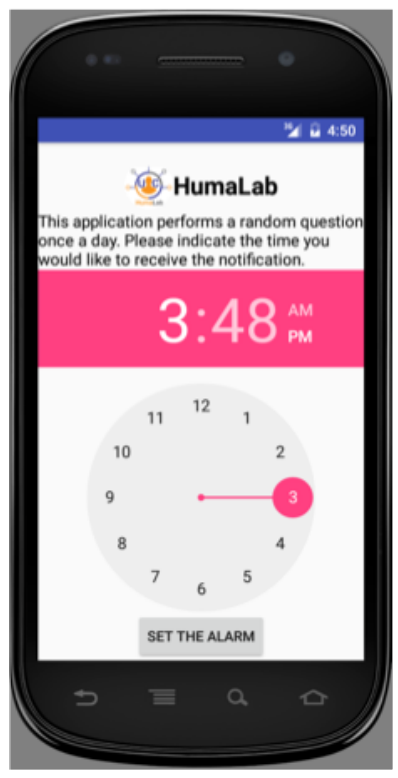

Figure 2. Mode FTN: set notification time.

2) Any Time Notification (ATN): in this case the notification is activated when the system detects that the phone is in use (unlocked).

The application was implemented for the Android system, and stores notification time, type of notification, answer time, selected answer and question.

\section{A. QuestionReport Interface}

QuestionReport is an application that was designed for senior users. According to available recommendations for designing interfaces for seniors [14], [19] (see Figure 3), we included features such as large font, tactile interaction, explicit messages, a simple interface, and high color contrast between font and background. Additionally, the application uses three different alarms that indicate the notification is active: visual (main bar), sound and vibration; because these sensory modalities may benefit people with sensory impairments [38].



Figure 3. QuestionReport Application: (a) Notification to remind answer the question of the day. (b) when the user presses the notification, the question of the day is presented.

\section{Methodology}

\section{A. Participants}

We recruited 18 participants (13 women, 5 men), both in Costa Rica and Chile. The average age of participants was 61.06 (min: 50, max: 81, standard deviation: 9.13). 6 participants were employed, 9 were retired and 3 were housewives. Out of the 18 participants, 1 had no digital skills, 6 had low digital skills, 8 had basic skills, and 3 had above basic digital skills, representing every possible category according to the DIGCOMP digital skills questionnaire [13].

\section{B. Assessment tools}

We applied four questionnaires. The questionnaires were the following ones: 
1) Questionnaire of intrinsic motivation (IMI) is a multidimensional self-report Likert-type rating scale used to assess the intrinsic motivation that a person has to do an activity [9], based on the Self-determinism Theory of motivation [30]. There are total of 6 subscales. We only used the pressure/tension subscale.

2) System usability scale (SUS) is a quick way to measure the overall usability of the system [8]. In this scale, scores below 60 indicate poor usability, while scores over 80 indicate very good usability [36].

3) DIGCOMP is a standardized instrument to measure digital competences, in which users are categorized into one of four possible groups, according to their digital skill levels: none, low, basic or above basic [13].

4) A questionnaire was applied to obtain the opinion of participants about notifications.

\section{Experiment}

To evaluate the prototype, each participant interacted with the application for eight days (four days using each notification mode) and participants had to answer one question per day, using the mobile application. Figure 4 shows the experimental phases, which were performed between May and August 2016.

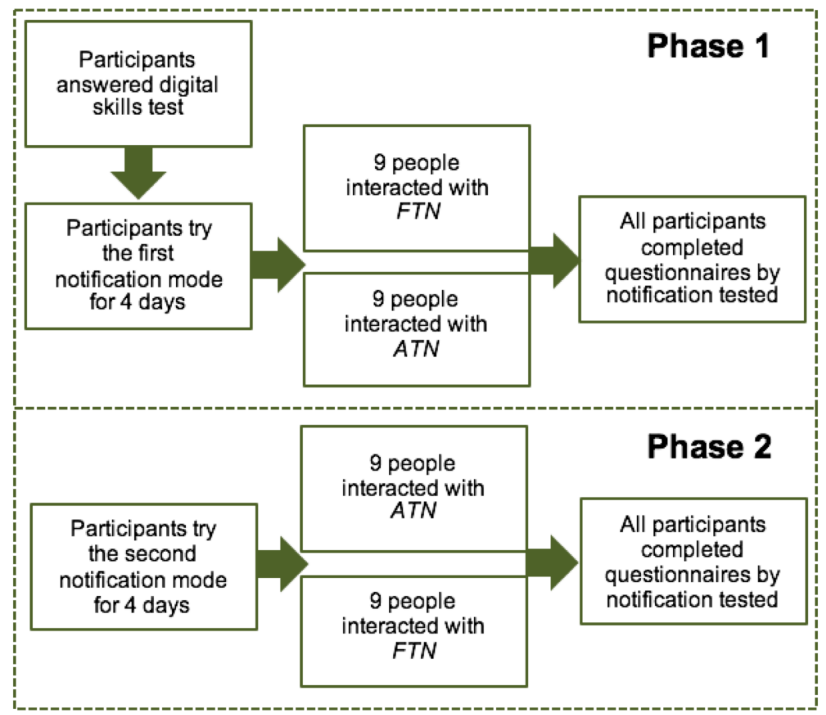

Figure 4. Phases of the experiment

The following activities were carried out with each participant:

1) One researcher gave a brief explanation about what is a notification and how it works.

2) An example of the application was shown to explain its operation (see Figure 5).

3) DIGCOMP test was applied.
4) The user interacted with the first application for 4 days; on the last day the participant completed the IMI survey and questionnaire (see Figure 6).

5) Then, the user interacted with the second application during 4 days. On the last day, we applied an IMI survey and questionnaire. Finally, the application usability was evaluated using the SUS survey.

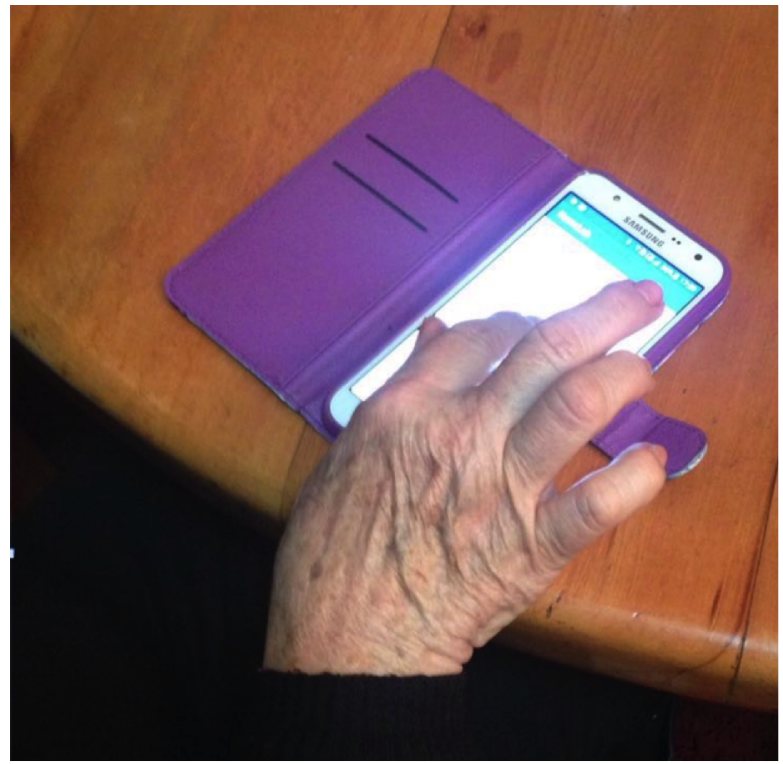

Figure 5. Older person interacting with the notification and application.

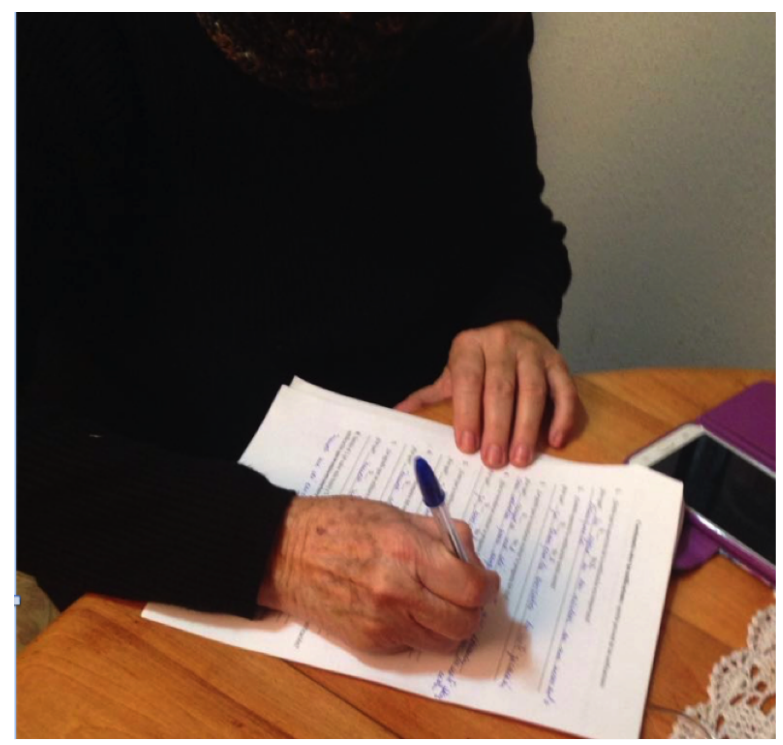

Figure 6. Evaluation process with elderly people

\section{Analysis}

We transcribed each questionnaire response, and analyzed them using thematic analysis [7]. The thematic map allowed 
us to see the topics emerge from responses in our survey (translated from Spanish). Some quotes are provided in the results. To calculate statistical significance between groups, we used the non-parametric Mann-Whitney $U$ test (significance level $=0.05$ ).

\section{REsults}

In this section, we review our research questions and provide our results. First, we mention several unexpected situations that arose during the development of the experiment. For participant P3, we did not obtain any information from the first phase of evaluation. An analysis indicated that the application stopped on some phones with version Android 4.2 or lower, because vibration permissions were needed. Participant P3 retook the first phase of evaluation. Participant P9 erased the application and notification data in the second stage of the experiment, and did not want to perform this stage again. Therefore for P9 only the information from the questionnaires and ATN data were included. P16 (with none digital skills) had acquired her first smartphone a few days before the experiment began. During the ATN stage, she did not use her phone at all, therefore receiving no notifications. During the FTN stage, the experimental data was deleted, possibly by an acquaintance who used her phone without her supervision. Therefore, we only have our observations regarding this participant, and no data.

We found that participants P7 and P11 did not answer one or two questions during the experiment. Additionally, participants P1, P3, P5, P10 and P17 turned off the phone, either because the phone was not charged or because the user voluntarily decided to turn it off; in these cases the activation time of notification was affected.

A. Do older adults prefer to choose a specific time to receive notifications or would they rather receive them at any time while they are using their device?

In order to know which is the best time to send the notification, the two notification modes were compared. In the question: From 1 (lowest) to 5 (highest), rate how much you liked the notification type, the score of the responses was 4.76 for FTN and 4.25 for ATN. These scores are similar, which is clear from the participants' comments regarding the appropriateness of notification time in each case. For example: P1 [ATN]: "The time was comfortable, because I don't have a job", P6 [ATN]: "I was connected at this time", P7 [FTN]: "The time was previously set, so it was not disruptive", and P11 [FTN]: "It was the time in which I was least busy". There was also not a significant difference between users that started the experiment by testing FTN and the ones that began with ATN. These results show that senior adults' contexts do influence the appropriate time to receive notifications, and that there is not an absolute best solution.
B. Is the time taken to answer an application notification related to receivers digital skills or occupation?

We classified the participants according to their digital skills (considering low, basic and above basic digital skills; as we only had one participant who had none digital skills) and occupation (in which we grouped those who were employed outside the home and those who were not). Table I shows that, when separating by digital skills, there is no statistically significant difference regarding response time between participants with low, basic and above basic skills.

Table I

TIME TAKEN TO ANSWER AN APPLICATION NOTIFICATION RELATED TO DIGITAL SKILLS

\begin{tabular}{cccc}
\hline \multicolumn{2}{c}{ Digital Skill } & \multirow{2}{*}{ FTN } & ATN \\
\cline { 1 - 3 } Level & Number & & \\
\hline Low & 6 & $\mathbf{0 0 : 2 6 : 0 1}$ & $01: 20: 40$ \\
Basic & 8 & $\mathbf{0 1 : 0 2 : 2 2}$ & $01: 54: 36$ \\
Above basic & 3 & $\mathbf{0 1 : 0 6 : 4 7}$ & $01: 37: 42$ \\
\hline
\end{tabular}

Table II presents the participants' results, grouped by their employment status. Unemployed participants (housewives and retired users) took longer to answer FTN, while employed users took longer to answer ATN. Their questionnaire answers provide explanations. For example: P4 [employed, ATN]: "It was disruptive because I was at work.", P11 [employed, ATN]: "I never realized I had gotten a notification, because I was working", and P11 [employed, FTN]: "It was the time in which I was least busy". Employed participants chose fixed time notifications at times in which they would not be at work or would not be busy (and therefore, were faster at answering), while the housewives/retired group had longer response times in both.

Table II

TIME TAKEN TO ANSWER AN APPLICATION NOTIFICATION RELATED TO EMPLOYMENT STATUS

\begin{tabular}{cccc}
\hline \multicolumn{2}{c}{ Occupation } & FTN & ATN \\
\hline Type & Number & & \\
\hline $\begin{array}{c}\text { Housewives } \\
\text { /retired }\end{array}$ & 12 & $01: 01: 39$ & $\mathbf{0 1 : 2 3 : 4 6}$ \\
Employed & 5 & $\mathbf{0 0 : 0 9 : 4 6}$ & $02: 17: 45$ \\
\hline
\end{tabular}

C. Does receiving a mobile application notification produce stress in older adults?

The experiment results show that elders did not feel stress or tension when the notification is activated. The Motivation Inventory results regarding Pressure and tension are presented in Table III. For both notification types, the results are quite positive: the notifications did not cause nervousness, pressure or stress. In the questionnaire answers, 
participants indicated that the notifications did not affect their mood or cause them stress or tension, e.g. P5 [with respect to notifications]: "It does not bother me", P10 [with respect to notifications]: "I was expecting it!", P6 [with respect to QuestionReport application]: “The questions were friendly".

Even though the notifications did not seem to be the cause of much stress, users did feel some pressure regarding the QuestionReport application. They felt that answering was an obligation that they had to accomplish, e.g. P1: "I felt more calm when I had answered, I got it over with".

Table III

PRESSURE/TENSION RESUlTS . BASED ON [30].

\begin{tabular}{lcc}
\hline \multicolumn{1}{c}{ Question $^{a}$} & FTN & ATN \\
\hline 1. I did not feel nervous at all & $\mathbf{6 , 4}$ & $\mathbf{6 , 5}$ \\
2. I was very relaxed & $\mathbf{6 , 6}$ & $\mathbf{6 , 7}$ \\
3. I did not feel pressured & $\mathbf{6 , 1}$ & $\mathbf{6 , 6}$ \\
4. I felt very tense & $\mathbf{2 , 7}$ & $\mathbf{3 , 2}$ \\
\hline
\end{tabular}

${ }^{a}$ Scale: 1 (strongly disagree) to 7 (strongly agree) for each question.

Therefore, according to the results of this study, we did not detect users to be stressed by receiving one notification per day. However, further study is necessary to determine stress levels (e.g. in-depth interviews) and how they vary according to number, type and time of notifications.

Besides, we inquired about the multimodal alarm notification asking: Do you like that sound and vibration is used as alarms or signals that the notification arrived? The responses of participants were positive, because all participants liked the multimodal form of notification (visual, vibration and sound), because it reminded them to answer the question and it was a warning sign. These results are consistent with [12], who propose that using several modalities are more effective than unimodal notifications for older people. Users commented: P1: "it got my attention", P6: "It made me doubly sure to be able to listen or feel the notification", P7: "It reminded me to answer". Participants were generally used to receiving cues about notifications, e.g. P10: "it is common to hear sounds made by social networks".

\section{DISCUSSION}

In this section, we discuss the lessons learned during this experiment and our insights for the design of applications that include notifications for senior adults.

\section{A. Digital skills, or ability to use notifications}

During our experiment, we faced several interesting, unexpected situations with participants with low digital skills. First, when we had just installed the application in the participants' smartphones, we briefly explained the experiment. We found that five participants (all with low digital skills, although regular users of applications such as
Whatsapp), did not know what a notification was nor how to open the notifications panel. They had seen symbols on the notification bar but did not know these were related to a new message in the application. Three of these participants also contacted the main researcher on the phone during the first day of evaluation of their first notification type, after hearing the activation of the notification, to ask how to use the notification. We believe this is related not only to their low digital skills, but also to the lack of confidence they feel in their knowledge about how to use their device. Perhaps for the same reason, participants with low digital skills scored the usability of the QuestionReport with a lower value than those with basic or above basic digital skills.

Another interesting, albeit unexpected situation, is that 5 of the users with low and basic digital skills had the habit of turning off their cell phones at certain times of the day. This caused the alarm notification to be delayed until the participant turned the phone on again.

Table IV

ITEMS OF ASSESSMENT RELATED TO DIGITAL SKILLS

\begin{tabular}{|c|c|c|c|c|}
\hline \multicolumn{2}{|c|}{ Digital Skill } & \multirow{2}{*}{$\begin{array}{l}\text { Turn off } \\
\text { phone }\end{array}$} & \multirow{2}{*}{$\begin{array}{l}\text { Contacted } \\
\text { researcer }\end{array}$} & \multirow{2}{*}{ SUS } \\
\hline Level & Number & & & \\
\hline Low & 6 & $50 \%$ & 3 & 75 \\
\hline Basic & 8 & $25 \%$ & 0 & 97 \\
\hline Above basic & 3 & $0 \%$ & 0 & 93 \\
\hline
\end{tabular}

\section{B. Notifications as a reminder}

Participants commented that having a notification reminded them to use the application and guided them to QuestionReport, which they would have not known how to open otherwise. P5: "Without the notification, I would not have remembered the question", P6: "It was a reminder, to prevent forgetting", P18: "The notification guided me to the application", P11 “... work does not allow me to see the phone frequently, so the reminder was important."

When senior adults see a need for technology, they are more inclined to start using it [27]. The results of this experiment suggest that most older adults perceive the notification as an aid to remembering the task. Also, one of the challenges for the design of systems aimed at older adults is to maintain their independence [35], so notifications can help elderly people to remember a task and not rely on others to help them.

\section{Effects of age}

To see whether as people age, effects on time taken to reply or preferences become more pronounced, we grouped our participants according to their age: those who were 5064 and those who were 65 and over (Table I). Although both age groups scored the usability of the application with similar scores, users 50-64 took less time to answer FTN 
than ATN, and they also were faster to answer FTN than users over 65. However, we attribute this to occupation rather than age, since five of these participants were working, while all of the 65 and over users were retired, and the employed participants felt ATN was an interruption when it was triggered at work.

Our results differ from [21], because we do not find evidence that elders have more technological stress when compared to younger age groups (the pressure/tension test was 6.04 for 50-64 year and 6.52 for 65 and over). We believe further study of the differences that appear as people age is important, however, we also believe that not finding differences is a good sign of the usability and design of our application.

Table V

TIME TAKEN TO ANSWER AN APPLICATION NOTIFICATION RELATED TO AGE

\begin{tabular}{cccc}
\hline Group & Number & FTN & ATN \\
\hline $50-64$ & 10 & $\mathbf{0 0 : 1 7 : 3 9}$ & $02: 02: 54$ \\
65 and over & 7 & $01: 42: 02$ & $\mathbf{0 1 : 0 6 : 2 5}$ \\
\hline
\end{tabular}

Technostress, as previously discussed, may appear due to a mismatch between the task and an individual's skills [2]. In our study, most participants did not experience technological stress. We believe this is due to three factors: (1) the application was created for elderly users (which is supported by the SUS scores, which were 85 for the 50-64 age group and 86.6 for those 65 and older, (2) the fact that the notification was only sent once a day, and (3) that all but one of our users had at least some digital skills.

\section{CONCLUSIONS}

This study presented a comparison of two notification modes, used to remind older adults to answer one daily question through a smartphone application. We measured the time taken to reply and recorded the participant' opinions, and analyzed them according to the participants' age, digital skills, and occupation status.

We found that the ideal time for older users to receive a notification depends on their activities e.g. occupation status, and that most users preferred notifications to be activated at a specific time each day when they are able to expect it. We also found that elderly users with low digital skills did not know the concept or functionality of notifications and several of them asked for the researchers' help on how to use notifications. All of them successfully learned how to use them during the experiment, but it is important that in future work, researchers consider that older users do not necessarily use notifications on their smartphones. Our participants did not express feeling pressured or stressed by the use of notifications (although this may change if we vary the number of notifications per day) and they liked the multimodal form of notification (visual, vibration and sound).

We believe it is essential to provide configuration of notifications to older users. This allows them to control the requirements of the application and decide according to their own needs. We also believe it was important, especially for older users, that we installed our application on their own smartphones, so we did not significantly disrupt their routines and could use the knowledge they already had about their devices.

Our evaluation has several limitations that we would like to acknowledge. First, it is limited by its small sample size. Second, the applications were tested for a short period of time and the experiment only evaluated two different types of notifications. Disentangling the effects of ability, motivation and trigger timing will require further experimentation and analysis. As future work, we would like to further study the influence of age, to learn which characteristics of aging influence acting upon notification triggers. We also intend to further study and manipulate notification-induced technostress, as we found that a small number of notifications (one per day) does not cause significant technostress, even in users who infrequently use their smartphones.

\section{ACKNOWLEDGMENTS}

This proyect was supported partially by CONICYTPCHA/Doctorado Nacional/13-21130661,2014-63140077, CONICIT and MICIT Costa Rica PhD scholarship grant, Universidad de Costa Rica and Fondecyt Proyect (Chile), grant: 1150365. We thank Esteban Centeno and Leonor Toro for their help with the experiment.

\section{REFERENCES}

[1] ADAMCZYK, P. D., AND BAILEY, B. P. If not now, when?: The effects of interruption at different moments within task execution. In Proceedings of the SIGCHI Conference on Human Factors in Computing Systems (New York, USA, 2004), CHI '04, ACM, pp. 271-278.

[2] AyYagari, R. Impact of information overload and tasktechnology fit on technostress. In Proceedings of Southern Association for Information Systems Conference (GA, USA, 2012), SAIS 2012.

[3] Barbosa, B., And Amaro, F. Too old for technology? how the elderly of lisbon use and perceive ict. The Journal of Community Informatics. 8, 1 (2012).

[4] Beltran, J. A. G., Leon, M. C., Martnez, A. I. G., AND Hipolito, J. I. N. Health emergency event notification system, towards to the seamless service mobility. In Serious Games and Applications for Health (SeGAH), 2014 IEEE 3rd International Conference on (May 2014), pp. 1-7.

[5] Bentley, F., And Tollmar, K. The power of mobile notifications to increase wellbeing logging behavior. In Proceedings of the SIGCHI Conference on Human Factors in Computing Systems (New York, NY, USA, 2013), CHI '13, ACM, pp. 1095-1098. 
[6] Betge-Brezetz, S., Dupont, M. P., Ghorbel, M., KAMGA, G. B., AND PIEKAREC, S. Adaptive notification framework for smart nursing home. In Conference of the IEEE Engineering in Medicine and Biology Society (Sept 2009), pp. 7244-7247.

[7] Braun, V., AND Clarke, V. Using thematic analysis in psychology. Qualitative Research in Psychology 3, 2 (2006), 77101 .

[8] Brooke, J. Sus-a quick and dirty usability scale. Usability evaluation in industry 189, 194 (1996), 4-7.

[9] CHOI, J., M. T. . M. A. Intrinsic motivation inventory: An adapted measure for schizophrenia research. Schizophrenia Bulletin 36, 5 (2010), 966976.

[10] Chua, W. Y., And Chang, K. T. An investigation of usability of push notifications on mobile devices for novice and expert users. In Hawaii International Conference on System Sciences (HICSS) (2016), IEEE, pp. 5683-5690.

[11] CRimmins, E. M. Trends in the health of the elderly. Annual Review of Public Health 25, 1 (2004), 79-98. PMID: 15015913.

[12] Emery, V. K., Edwards, P. J., Jacko, J. A., Moloney, K. P., Barnard, L., Kongnakorn, T., SAinfort, F., AND SCOTT, I. U. Toward achieving universal usability for older adults through multimodal feedback. In Proceedings of the 2003 Conference on Universal Usability (New York, NY, USA, 2003), CUU '03, ACM, pp. 46-53.

[13] FERRARI, A. Digital competence in practice: An analysis of frameworks. Tech. rep., Research Centre of the European Commission, 92012.

[14] Ferron, M., Mana, N., And Mich, O. Mobile for older adults: Towards designing multimodal interaction. In Proceedings of Conference on Mobile and Ubiquitous Multimedia (New York, USA, 2015), MUM '15, ACM, pp. 373-378.

[15] Fogg, B. A behavior model for persuasive design. In Proceedings of the 4th International Conference on Persuasive Technology (New York, NY, USA, 2009), Persuasive '09, ACM, pp. 40:1-40:7.

[16] French, J. R. P. J., Rodgers, W., And Cobb, S. Adjustment as person-environment fit. Basic Books, New York, USA, 1974.

[17] García-Peñalvo, F. J., Conde, M. Á., And MatellánOlIVERA, V. Learning and Collaboration Technologies. Technology-Rich Environments for Learning and Collaboration: HCI International. Springer International Publishing, Cham, 2014, ch. Mobile Apps for Older Users - The Development of a Mobile Apps Repository for Older People, pp. 117-126.

[18] Giusti, L., Mencarini, E., And Zancanaro, M. "luckily, i don't need it": Elderly and the use of artifacts for time management. In Proceedings of Human-Computer Interaction: Extending Boundaries (New York, NY, USA, 2010), NordiCHI '10, ACM, pp. 198-206.
[19] Iglesias, R., Gomez de Segura, N., AND Iturburu, M. The elderly interacting with a digital agenda through an rfid pen and a touch screen. In Proceedings of International Workshop on Media Studies and Implementations That Help Improving Access to Disabled Users (New York, USA, 2009), MSIADU '09, ACM, pp. 63-70.

[20] IQbal, S. T., AND Bailey, B. P. Oasis: A framework for linking notification delivery to the perceptual structure of goal-directed tasks. ACM Trans. Comput.-Hum. Interact. 17, 4 (Dec. 2010), 15:1-15:28.

[21] Jane-Frances, O., And Simeon, O. Technostress in the age of information communication technology: A case study of distance education. Educational Research 2 (2011), 1654 1660 .

[22] Leonardi, C., Mennecozzi, C., Not, E., Pianesi, F., AND ZANCANARo, M. Designing a familiar technology for elderly people. Gerontechnology 7, 2 (2008).

[23] Mehrotra, A., Musolesi, M., Hendley, R., And PeJOVIC, V. Designing content-driven intelligent notification mechanisms for mobile applications. In Proceedings of Conference on Pervasive and Ubiquitous Computing (New York, USA, 2015), UbiComp '15, ACM, pp. 813-824.

[24] Neves, B. B., Franz, R. L., Munteanu, C., Baecker, R., AND NGO, M. "my hand doesn't listen to me!": Adoption and evaluation of a communication technology for the 'oldest old'. In Proceedings of Conference on Human Factors in Computing Systems (New York, USA, 2015), CHI '15, ACM, pp. 1593-1602.

[25] OH, H., JALALI, L., AND JAIN, R. An intelligent notification system using context from real-time personal activity monitoring. In 2015 IEEE International Conference on Multimedia and Expo (ICME) (June 2015), pp. 1-6.

[26] Organization, W. H. Definition of an older or elderly person. Accessed: 2016-06-06.

[27] Peek, S. T., Wouters, E. J., Van Hoof, J., LuiJkX, K. G., Boeise, H. R., And Vrijhoef, H. J. Factors influencing acceptance of technology for aging in place: A systematic review. International Journal of Medical Informatics 83, 4 (2014), 235 - 248.

[28] Portet, F., Vacher, M., Golanski, C., Roux, C., And MeILlon, B. Design and evaluation of a smart home voice interface for the elderly: Acceptability and objection aspects. Personal Ubiquitous Comput. 17, 1 (Jan. 2013), 127-144.

[29] Pribbenow, K. Maintaining balance: Mile-high expectations vs. technostress. In Proceedings of Conference on User Services: Mile High Expectations (New York, NY, USA, 1999), SIGUCCS '99, ACM, pp. 180-184.

[30] Ryan, R. M., AND DeCI, E. L. Self-determination theory and the facilitation of intrinsic motivation, social development, and wellbeing. American Psychologist 55 (2000), 6878.

[31] SawasdeE, S., AND Pumrin, S. Elderly care notification system using hand posture recognition. In Digital Information and Communication Technology and it's Applications (DICTAP) (May 2014), pp. 304-309. 
[32] Singh, S., And Bajorek, B. Defining elderly in clinical practice guidelines for pharmacotherapy. Pharmacy Practice 12, 4 (2014), $489-9$.

[33] Soto-Mendoza, V., García-Macías, J. A., Chávez, E., Martínez-García, A. I., Favela, J., SerranoAlvarado, P., AND Rojas, M. R. Z. N. Design of a predictive scheduling system to improve assisted living services for elders. ACM Trans. Intell. Syst. Technol. 6, 4 (July 2015), $53: 1-53: 31$.

[34] Stuck, A. E., Walthert, J. M., Nikolaus, T., Bla, C. J., Hohmann, C., AND Beck, J. C. Risk factors for functional status decline in community-living elderly people: a systematic literature review. Social Science \& Medicine 48, 4 (1999), 445 - 469.

[35] Sun, H., Florio, V. D., Gui, N., and Blondia, C. Promises and challenges of ambient assisted living systems. In Information Technology: New Generations, 2009. ITNG '09. Sixth International Conference on (April 2009), pp. 1201-1207.

[36] Tullis, T., And Albert, W. Measuring the User Experience: Collecting, Analyzing, and Presenting Usability Metrics. Morgan Kaufmann Publishers Inc., CA, USA, 2008.

[37] UmezU, K., K. T., AND A., O. Context-based barrier notification service toward outdoor support for the elderly. International Journal of Computer Science \& Information Technology (IJCSIT) (2013), 23-34.

[38] Warnock, D., McGee-Lennon, M., And Brewster, S. Multiple notification modalities and older users. In Proceedings of Human Factors in Computing Systems (New York, NY, USA, 2013), CHI '13, ACM, pp. 1091-1094.

[39] Waycott, J., Vetere, F., Pedell, S., Kulik, L., OzAnne, E., Gruner, A., And Downs, J. Older adults as digital content producers. In Proceedings of the SIGCHI Conference on Human Factors in Computing Systems (New York, NY, USA, 2013), CHI '13, ACM, pp. 39-48.

[40] Weber, D., Shirazi, A. S., AND Henze, N. Towards smart notifications using research in the large. In International Conference on Human-Computer Interaction with Mobile Devices and Services Adjunct (New York, USA, 2015), MobileHCI '15, ACM, pp. 1117-1122.

[41] Westermann, T., Möller, S., And Wechsung, I. Assessing the relationship between technical affinity, stress and notifications on smartphones. In International Conference on Human-Computer Interaction with Mobile Devices and Services Adjunct (New York, USA, 2015), MobileHCI '15, ACM, pp. 652-659.

[42] Wickens, C. D. Multiple resources and performance prediction. Theo. Issues Ergon. Sci. 3, 2 (2002), 159177.

[43] YAnkner, B. A., Lu, T., And Loerch, P. The aging brain. Annu Rev Pathol. 8 (2008), 41 - 66. 